\title{
Mimosa diplotricha (Fabaceae) Recruits Native Pollinators, But Does it Matter?
}

\section{1, 2*EGBON, IN; ${ }^{1-3}$ NZIE OP; ${ }^{2}$ ROTIMI, J}

\author{
${ }^{\prime}$ Insect Ecology and Diversity Unit, ${ }^{2}$ Department of Animal and Environmental Biology, University of Benin, PMB 1154 Benin City, Nigeria \\ ${ }^{3}$ Hawkesbury Institute for the Environment, Western Sydney University, Locked Bag 1797, Penrith NSW 2751, Australia \\ "Corresponding Author Email: ikponmwosa.egbon@uniben.edu
}

\begin{abstract}
Here an invasive alien weed Mimosa diplotricha, which attracts native pollinators to its flowers, was studied to establish the composition, diversity and the pattern of visitation of native flower-visiting species found on the weed as it expands its range unabatedly in Nigeria. From five randomly selected quadrats of $2 \mathrm{~m} \times 2 \mathrm{~m}$, repeated fourteen times, the floral visitors of $M$. diplotricha were sampled. Using diversity indices, non-parametric species estimators, Whittaker and Bray Curtis similarity indices, the composition and diversity of floral visiting bees and allied insects were reported. Thirteen insect taxa were encountered from a total of 1548 individuals in three Orders, albeit of low diversity in which the majority of floral visitors (or pollinators) were hymenopterans: the main being Chalicodoma species, followed by Xylocopa species, X. senior, and Apis mellifera. Non-parametric estimators revealed a high sampling efficiency of the true species visiting mimosa between sunrise and noon. That the floral resources of $M$. diplotricha supported high abundance of few species and some species with low abundance indicate that those of the latter case were casual visitors. In sum, that the population of $M$. diplotricha is still expanding in Nigeria against the backdrop of their utilisation by native pollinators is suggestive of a continual recruitment of the pollinators, which may prefer the novel host within a mosaic of widely scattered native flowering plants. Further investigations of pollinators' choices may be apt to understand the true impact of invasive alien flowering weeds on native pollinators and crop productivity.
\end{abstract}

DOI: https://dx.doi.org/10.4314/jasem.v23i12.27

Copyright: Copyright (C) 2019 Egbon et al. This is an open access article distributed under the Creative Commons Attribution License (CCL), which permits unrestricted use, distribution, and reproduction in any medium, provided the original work is properly cited.

Dates: Received: 30 November 2019; Revised: 20 December 2019; Accepted: 23 December 2019

Keywords: Invasive alien weed, pollen, nectar, bees

Some plants' flowers are visited by different animals in search of nutrients from floral resources like pollen and nectar (Gess and Gess, 2014). Such floral visitors are mostly insects, which render ecosystem services of pollination. To many crops and wild plants, insect pollination is a key factor for their sexual reproduction (Chittka and Schürkens, 2001; Gess and Gess, 2014). Besides, such pollinators provide calories and micronutrients for humans and other animals (Gess and Gess, 2014), and these are some of the services that make them key components of a balanced ecological system. Nonetheless, several ecological systems are continually being altered through human influence, like the introduction of alien plants some of which become harmful to recipient ecosystems (Williamson and Fitter, 1996; Chittka and Schürkens, 2001).

In an ever-expanding range of non-native invasive flowering plants, not only are native plants physically suppressed, they are also suppressed through an ecological denial of essential services of the pollinators (Chittka and Schürkens, 2001; Ghazoul, 2002). Although largely anecdotal, the domino effects of non-pollinated native plants could lead the dependent animal taxa down an extinction vortex as the resultant resources (fruits and seeds, whose production solely rely on insect pollination) decline in response to a decline in, or an absence of, the pollinators' services (cf. Chittka and Schürkens, 2001).

Mimosa diplotricha C. Wright ex Sauvalle is a nonnative, thorny flowering leguminous shrub that is native to tropical South America, but introduced to Nigeria and has been listed as one of the world's 100 worst invasive species (Lowe, 2000). It forms a dense impenetrable stems armed with broad-based prickles and it is widely distributed in Nigeria (Ekhator et al., 2013). With its pale purple flowers borne on its subglobose pedunculate head, the flowers of $M$. diplotricha dominate its invaded habitats provided water availability remains unhindered (Lonsdale, 1988; Ekhator et al., 2013). Several studies have shown the attractiveness of native pollinators to invasive alien species including mimosa (Ghazoul, 2002; Memmott and Waser, 2002; Chittka and Schurkens, 2001; Moragues and Traveset, 2005; Stout et al., 2006; Lopezaraiza-Mikel et al., 2007; Forester, 2010; Gess and Gess, 2014; Stout and Tiedeken, 
2017). Mimosa diplotricha may be a resource for native pollinators that are globally on a decline, but may invariably continue to deprive native plants off their pollinators (Chittka and Schürkens, 2001; Ghazoul, 2002). The worldwide decline of pollinators is perhaps as a result of changes in land use patterns driven by human activities that may be the key driver responsible for the loss of nectar-rich plants (Chittka and Schürkens, 2001; Beismeijer et al., 2006; Stout and Tiedeken, 2017). Such decline of pollinators can systematically lead to a corresponding decline in native plants that rely on these pollinators. Recruitments of native pollinators by non-native flowering invaders in a mosaic of native and invasive plants may deprive the former of the pollination services needed to effectively reproduce, if they rely mainly on insect pollination.

Consequently, it is imperative to sustain native pollinators by growing native plants that attract and reward flower-visiting insects (Owen, 1991). In the absence of such efforts, however, invasive alien plants could provision and reward these pollinators, alas, even better than the native plants given the abundant flowers at their disposal (see Chittka and Schürkens, 2001). Unlike the native plants, which may be confoundedly locked or widely scattered within a mosaic of different flowering native plants making the native flower-bearers energetically expensive for the pollinators to exploit, the invasive alien flowering plants can provide a homogenous stand of luxuriant floral resources. Such a 'flower-generous' invaders, like mimosa, can create a sea of alien flowers that traps native pollinators away from native plants as less energy would be intuitively required to collect floral resources from a focal point of homogenous stands than from widely scattered native ones. The crux here is that in Nigeria, M. diplotricha is gradually becoming a dominant weed (Ekhator et al., 2013), which attracts native pollinators; however, there is paucity of information on the true species composition and diversity of pollinators utilising its floral resource(s). With focus on an invaded plot at the University of Benin, which is situated in one of southern Nigeria's most-impacted areas where the invader is observably proliferating at an alarming rate (see Ekhator et al., 2013), the knowledge gap was addressed. Furthermore, the ecological implications of native pollinators' use of an invasive plant's floristic resources were discussed.

\section{MATERIAL AND METHODS}

Study area: The study was conducted between May and June 2013 on M. diplotricha that predominated an area of about 300 feet on both sides of an approximately two kilometer belt transect (road) situated at the northern flank of University of Benin (commonly known as 'Capitol'). The GPS coordinates of the site, as recorded using GARMIN $72 \mathrm{H}$ handheld device, were $6^{\circ} 23^{\prime} 58.8^{\prime \prime} \mathrm{N}$ and $5^{\circ} 38^{\prime} 1.4^{\prime \prime} \mathrm{E}$. Similar to the seasonality across southern Nigeria, the study area is marked with two -wet and dry- seasons. The plant community structure of the area was mostly pristine until it was recently altered $(<5$ years, prior to this study) with the construction of the road; however an extended part of the surrounding vegetation had always been cultivated for food crops by the locals.

Study species: Mimosa diplotricha is an annual scrambling leguminous vine with recurved hooks that facilitate its ability to entangle neighboring plants in several open and disturbed ecosystems like roadsides and forest fringes (for other relevant references, see review Ekhator et al., 2013). The plant remains luxuriant during the wet seasons (March to October) and produces flowers during the late wet season and early dry season in Nigeria (Ekhator et al., 2013). Its flowers remain open for few days, while provisioning floral visitors (pollinators) with at least a reward pollen, which adhere onto the insects' bodies.

Insect sampling: Sampling was conducted from May to June as it coincides with the peak of flowering plants of agricultural and economic importance. Samples of insect species visiting flowers of the invasive alien plant from sunrise to afternoon were collected twice weekly over a period of seven weeks; no attention was given to crepuscular or nocturnal visitors. The flower-visiting species were opportunistically collected using sweep net, but the abundance of the floral visitors was determined through visual observation in five randomly selected sites with numerous flowers of mimosa. The visual observations and counts were confined to predetermined quadrats of $2 \mathrm{~m} \times 2 \mathrm{~m}$. Integrating sweep net collections, visual observation/counting methods helped eliminate any remarkable damage that the sweep-net sampling alone could have had on the plant's parts (see Swart et al., 2017 for rationale). Taken together, the effective sampling area was a total of $10 \times 10 \mathrm{~m}^{2}$ per sampling event. The floral visitors in each subplot were visually counted hourly from $8: 00 \mathrm{~h}$ to 13:00h, but within each sampling hour, each subplot was sampled for twelve minutes. The sampling periods was chosen to minimise negative influences of fatigue on sampling efficiency.

The insect specimens that were collected using a sweep net, which is quick and has short sorting time (Swart et al., 2017), were emptied into killing jars that were charged with three drops of a killing agent, ethyl acetate. Collected specimens were mounted in insect 
boxes for further identification in the laboratory using pictorial, and identification keys (Bland and Jaques, 1978; Gess and Gess, 2014). Mounted and identified specimens also served as a reference for further data collection in situ. The number of reference specimens was infinitesimally small and not enough to influence the natural population or subsequent counts of the floral visitors.

Statistical analysis: Species abundance data, collected over several sampling time (an equivalent of 70 manhours), were summarised in a tabular form from which species richness, diversity indices (such as Shannon, Evenness, among others) were computed using PAST $^{\mathrm{TM}}$ (version 3). Compositional similarities among sampling events were tested using a nonparametric Analysis of Similarity (ANOSIM), which is based on mean ranking between groups and within groups. To calculate the percentage contribution of each species to the average dissimilarities among sampling events, SIMPER analysis was conducted using PAST. Percentages of the true species richness of pollinators that potentially utilise $M$. diplotricha were calculated using nonparametric estimators: Chao2, first and second order Jackknife and bootstrap estimates, for the entire samples and period of samples. Other graphical representations like species and individual rarefaction curves, and rank-abundance curves (for both the collections from the entire sampling events and sampling periods within events) were also used. Furthermore, a two-way hierarchical clustering subjected to Bray-Curtis similarity index was used to establish the similarities of visiting pollinators across the five sampling times and presented as dendrograms. Species diversity and dominance indices for any pair of sampling periods were compared using diversity ttest.

\section{RESULTS AND DISCUSSION}

In this study, a composition of 13 taxa, largely hymenopterans, were encountered on the flowers of $M$. diplotricha and all amounted to 1,548 individuals after fourteen repeated samples (Table 1). Besides insects in the order Hymenoptera, members of the orders Diptera $(0.07 \%)$ and Lepidoptera $(0.3 \%)$ also visited mimosa flowers (Table 1). Diversity indices for the entire sample yielded a dominance (D) of 0.3375 , a Shannon $(\mathrm{H})$ index of 1.482 (that is, an effective species diversity, $\mathrm{e}^{\wedge \mathrm{H}}$, of 4.4 species) and evenness (E) index of 0.3385 . Using sequential Bonferroni significance $p$-values, analysis of similarity (ANOSIM) showed significant (ANOSIM: $p<0.001$; $\mathrm{R}=0.228$; Table 2 ) differences in species count across sampling events. Similarity percentage (SIMPER) showed that Chalicodoma species contributed $45 \%$ of the total number of pollinators that visited $M$. diplotricha (Table 3) and in addition to three other species, namely Xylocopa species, X. senior, and Apis mellifera, up to $85 \%$ species contribution was recorded. On the contrary, the least contributing visitors were Helophilus pendulus, X. caffra, Eremnophila species, Polistes species, and Danaus species, which individually had less than a percentage contribution, and collectively contributed less than $5 \%$ to the total number of floral visitors on $M$. diplotricha. Individual rarefaction showed that the chances of finding a new species of floral visitor at the end of the survey started approaching the asymptote when about one-third of the total individuals collected were sampled (Fig. 1). Sample rarefaction also conformed to this pattern after eighth sample (Fig. 2), while far fewer new species were encountered afterwards. True species richness as computed using the non-parametric estimators: Chao2, first and second order Jackknife and bootstrap values gave values of 13, 13.9, 14.0 and 13.5 , respectively; which revealed that between 93$100 \%$ of the true species that visit $M$. diplotricha were sampled. Chao2 yielded the lowest value which corresponds to the highest percentage $(100 \%)$, while Jackknife2 estimate predicted the inventory completeness as $92.8 \%$. Rank abundance curve showed that more than half of the species encountered occurred in rarity unlike others like Chalicodoma species, Xylocopa species and Apis mellifera (Fig. 3). Xylocopa caffra and $H$. pendulus were doubleton and singleton, respectively, which were ranked low on the abundance distribution curve that showed a significant $(p<0.05)$ alpha of 1.945 (Fig. 3). Hierarchical clustering showed that the fourteen samples largely clustered into two clades with $62 \%$ dissimilarity (Fig. 4 ) as the compositions of the initial samples, with the exception of the tenth one, were largely similar unlike the later samples.

At different periods, the composition of visiting pollinators varied significantly $(p<0.001, \mathrm{R}=0.14$ based on Bray-Curtis similarity index) and, those that visited at $0830 \mathrm{~h}$ were significantly (ANOSIM: $p<$ 0.01 ) different from those encountered in other periods, which were in themselves not significantly different (ANOSIM: $p>0.05$ ). Observed dominance was high at $0830 \mathrm{~h}$ and $1230 \mathrm{~h}$ for a few species relative to others; however, at $1030 \mathrm{~h}$ the community structure of visiting pollinators had the highest diversity (Shannon $\mathrm{H}$ ) index of 1.53 (with an effective diversity of 4.6 species) unlike the least value of 1.34 (with an effective diversity of 3.8 species) encountered at 12:30h (Table 4). 
Table 1 Species composition (and relative abundance (\%)) of pollinators that visited the purple-coloured flowers of Mimosa diplotricha in a fourteen-sample survey

\begin{tabular}{|c|c|c|c|c|c|c|c|c|c|c|c|c|c|c|c|c|}
\hline \multirow[b]{2}{*}{ Family $^{+}$} & \multirow[b]{2}{*}{ Species } & \multicolumn{14}{|c|}{ Sampling events } & \multirow[b]{2}{*}{ Total (\%) } \\
\hline & & 1 & 2 & 3 & 4 & 5 & 6 & 7 & 8 & 9 & 10 & 11 & 12 & 13 & 14 & \\
\hline \multirow[t]{2}{*}{ Apidae } & Apis mellifera & 0 & 0 & 0 & 4 & 5 & 0 & 2 & 31 & 20 & 3 & 14 & 18 & 18 & 0 & $115(7.4)$ \\
\hline & Amegilla sp. & 0 & 0 & 0 & 4 & 24 & 0 & 5 & 2 & 4 & 5 & 1 & 2 & 2 & 0 & $49(3.2)$ \\
\hline \multirow{4}{*}{ Anthophoridae } & Xylocopa caffra & 0 & 0 & 0 & 0 & 0 & 0 & 0 & 0 & 0 & 0 & 0 & 1 & 1 & 0 & $2(0.13)$ \\
\hline & Xylocopa latipes & 4 & 1 & 4 & 0 & 1 & 1 & 0 & 0 & 0 & 0 & 0 & 0 & 0 & 0 & $11(0.7)$ \\
\hline & Xylocopa senior & 23 & 54 & 28 & 0 & 5 & 1 & 4 & 0 & 4 & 1 & 0 & 1 & 1 & 2 & $124(8.0)$ \\
\hline & Xylocopa sp. & 40 & 96 & 89 & 8 & 13 & 15 & 6 & 3 & 13 & 29 & 10 & 1 & 1 & 2 & $326(21.1)$ \\
\hline \multirow[t]{3}{*}{ Megachilidae } & Chalicodoma sp. & 63 & 79 & 106 & 60 & 83 & 82 & 98 & 13 & 60 & 54 & 37 & 32 & 32 & 18 & $817(52.8)$ \\
\hline & Megachile sp.1 & 4 & 0 & 20 & 1 & 6 & 1 & 5 & 1 & 4 & 4 & 1 & 4 & 4 & 0 & $55(3.6)$ \\
\hline & Megachile sp.2 & 0 & 0 & 0 & 0 & 11 & 0 & 0 & 0 & 0 & 8 & 5 & 0 & 0 & 1 & $25(1.6)$ \\
\hline Sphecidae & Eremnophila sp. & 2 & 1 & 4 & 1 & 1 & 0 & 1 & 0 & 0 & 1 & 0 & 0 & 0 & 0 & $11(0.7)$ \\
\hline Vespidae & Polistes sp. & 0 & 0 & 0 & 1 & 0 & 0 & 0 & 0 & 2 & 2 & 0 & 1 & 1 & 0 & $7(0.5)$ \\
\hline Syrphidae $^{\mathrm{d}}$ & Helophilus pendulus & 0 & 0 & 0 & 0 & 0 & 0 & 0 & 0 & 1 & 0 & 0 & 0 & 0 & 0 & $1(0.07)$ \\
\hline \multirow[t]{4}{*}{ Nymphalidae $^{1}$} & Danaus sp. & 0 & 0 & 0 & 3 & 0 & 0 & 0 & 0 & 0 & 1 & 0 & 0 & 0 & 1 & $5(0.3)$ \\
\hline & Total individuals $\mathrm{a}$ & 136 & 231 & 251 & 82 & 149 & 100 & 121 & 50 & 108 & 108 & 68 & 60 & 60 & 24 & 1548 \\
\hline & Number of species ${ }^{b}$ & 6 & 5 & 6 & 8 & 9 & 5 & 7 & 5 & 8 & 10 & 6 & 8 & 8 & 5 & 13 \\
\hline & Sample intensity ${ }^{c}$ & 22.7 & 46.2 & 41.8 & 10.3 & 16.6 & 20 & 17.3 & 10 & 13.5 & 10.8 & 11.3 & 7.5 & 7.5 & 4.8 & 119.1 \\
\hline
\end{tabular}

$$
\text { Note: superscripts: }{ }^{+} \text {Orders are mainly Hymenoptera, exceptfor }{ }^{d} \text { Diptera and }{ }^{l} \text { Lepidoptera }{ }^{c} \text { sample intensity is equal to }{ }^{a / b}
$$

Table 2. Analysis of similarity (ANOSIM) of species composition across sampling days based on Bray Curtis similarity index

\begin{tabular}{|c|c|c|c|c|c|c|c|c|c|c|c|c|c|}
\hline & & & ANOSI & $p$-values & sing sequ & tial Bonf & oni signi & ance bas & on Bray & urtis sim & rity index & & \\
\hline & day1 & day2 & day3 & day4 & day5 & day6 & day7 & day8 & day9 & day10 & day11 & day12 & day13 \\
\hline $\begin{array}{l}\text { day1 } \\
\text { day2 }\end{array}$ & 0.1159 & & & & & & & & & & & & \\
\hline day3 & 0.0576 & 0.5501 & & & & & & & & & & & \\
\hline day4 & 0.1104 & 0.0684 & 0.0618 & & & & & & & & & & \\
\hline day5 & 0.0078 & 0.0092 & 0.0062 & 0.0247 & & & & & & & & & \\
\hline day6 & 0.15 & 0.0837 & 0.0763 & 0.4719 & 0.0161 & & & & & & & & \\
\hline day7 & 0.0733 & 0.0832 & 0.0779 & 0.4705 & 0.0301 & 0.5613 & & & & & & & \\
\hline day8 & 0.0081 & 0.0303 & 0.034 & 0.0809 & 0.0074 & 0.0351 & 0.046 & & & & & & \\
\hline day9 & 0.2704 & 0.08 & 0.0784 & 0.5661 & 0.0173 & 0.3698 & 0.3611 & 0.1867 & & & & & \\
\hline day10 & 0.3606 & 0.0227 & 0.018 & 0.4301 & 0.1031 & 0.0723 & 0.0227 & 0.016 & 0.5039 & & & & \\
\hline day11 & 0.1329 & 0.0067 & 0.0072 & 0.1929 & 0.0088 & 0.0313 & 0.0308 & 0.0922 & 0.2737 & 0.2528 & & & \\
\hline day12 & 0.0084 & 0.0082 & 0.0091 & 0.026 & 0.0084 & 0.0227 & 0.0234 & 0.1282 & 0.0859 & 0.0263 & 0.1977 & & \\
\hline day13 & 0.0076 & 0.0089 & 0.0099 & 0.0248 & 0.0075 & 0.022 & 0.0256 & 0.1299 & 0.0837 & 0.0241 & 0.2044 & 0.9834 & \\
\hline day14 & 0.0385 & 0.093 & 0.074 & 0.3805 & 0.0176 & 0.2821 & 0.281 & 0.0413 & 0.388 & 0.0568 & 0.0587 & 0.1187 & 0.1155 \\
\hline
\end{tabular}


Sample rarefaction curve of species encountered for the five sampling periods was far from reaching its asymptote at the fifth sampling time (Fig 5); however, individual rarefaction curves for all sampling periods showed a less likelihood of encountering new species at $1030 \mathrm{~h}$ than at any other periods, which were either far from reaching their respective asymptotes (i.e., at $0830 \mathrm{~h}$ and $1230 \mathrm{~h}$ ) or approaching asymptotes with lower number of visiting species ((i.e., $0930 \mathrm{~h}$ and 1130 h; Fig. 6). Using the non-parametric estimator (Chao1), only $94 \%$ and $88 \%$ of the respective alpha diversities at $0830 \mathrm{~h}\left(\mathrm{~S}_{\mathrm{obs}}=9 ; \mathrm{S}_{\text {est }}=9.5\right)$ and $1230 \mathrm{~h}$ $\left(\mathrm{S}_{\mathrm{obs}}=11 ; \mathrm{S}_{\mathrm{est}}=12.5\right)$ were collected unlike the others where $100 \%$ were estimated. The average percentages of species unaccounted for in the entire periods (quadrat richness) predicted that about $10 \%$ of the pollinators that actually visit mimosa was not sampled as Chao2, Jackknife1, Jackknife2 and Bootstrap estimates had values of 13.8, 14.6, 15.8, and 13.7, respectively.

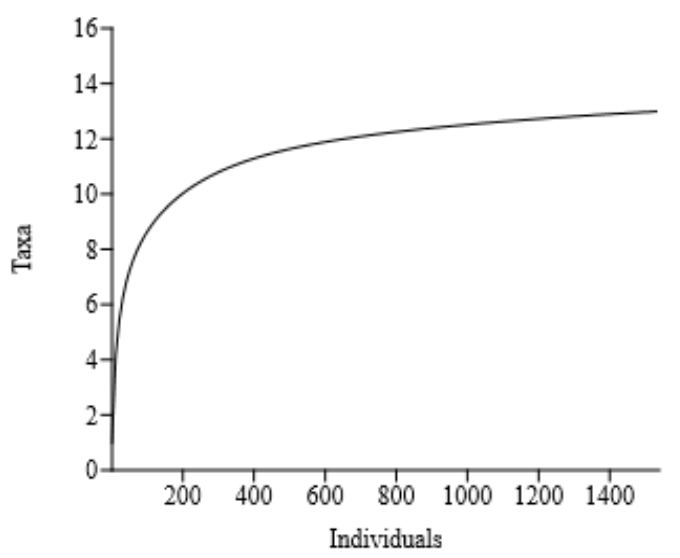

Fig 1. Individual rarefaction curve for one of many possible orderings of 1,548 individual of floral visitors on flowers of $M$. diplotricha collected from an intensive census of five preselected $2 \times 2 \mathrm{~m}^{2}$ plots of an invaded field. The cumulative number of insect species ( $y$-axis) is plotted as a function of the cumulative number of individual ( $x$-axis).

Diversity t-test revealed that while there were large similarities between pairs of sampling periods in dominance (D), the $\mathrm{H}$ indices were statistically different. Shannon $(\mathrm{H})$ index at $1130 \mathrm{~h}(1.51 \pm 0.00)$ differed significantly (diversity $t=2.03, p=0.04$ ) from that observed at $1230 \mathrm{~h}$; however, the dominance (D) for both periods were not different $(\mathrm{t}=1.9, p=$ 0.055). Similar pattern occurred between $1030 \mathrm{~h}$ and $1230 \mathrm{~h}$ with a Shannon H index of $1.55 \pm 0.00$ and 1.34 \pm 0.00 respectively $(t=2.20, p=0.03)$, while their respective dominance $\mathrm{D}$ index of $0.32 \pm 0.00$ and 0.38 \pm 0.00 were not significantly different $(t=1.78, p=$ $0.07)$. Diversity indices for others possible pairings did not differ significantly $(p>0.05)$. A low heterogeneity of pollinators was obtained with a Whittaker index of 0.226 .

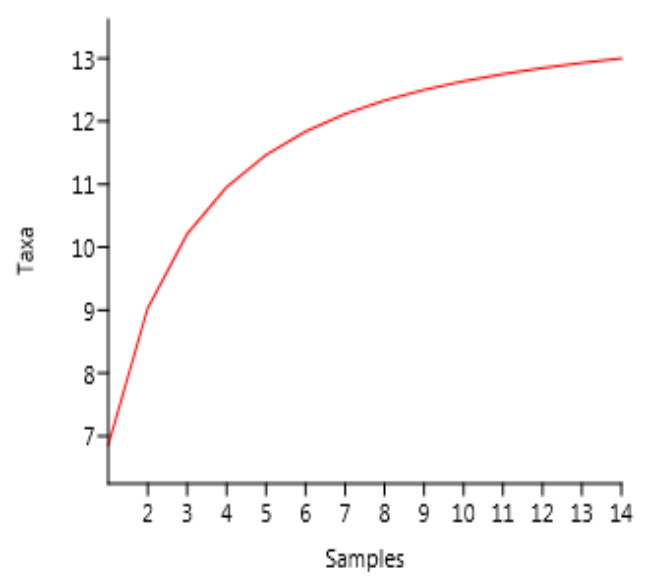

Fig 2. Sample rarefaction curve for one of many possible orderings of fourteen samples of visiting pollinators on flowers of $M$. diplotricha. The cumulative number of insect species ( $y$-axis) is plotted as a function of the cumulative samples ( $x$-axis).

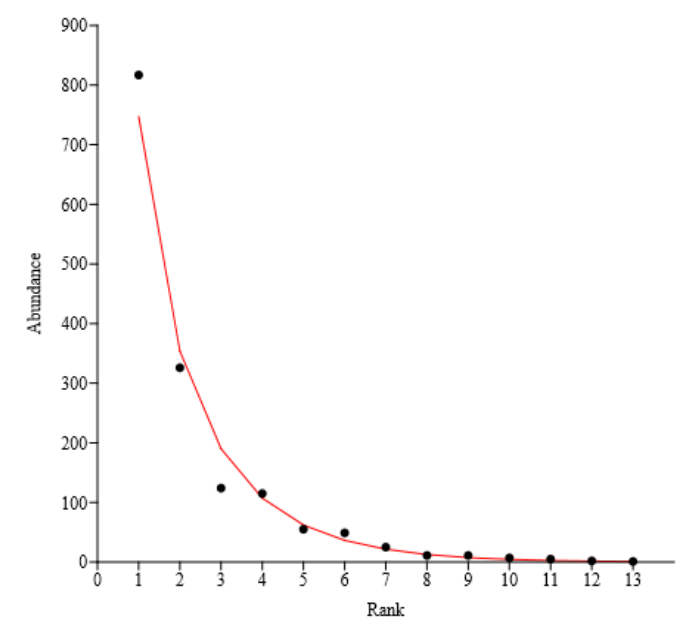

Fig 3. Rank-abundance curve of pollinators that visited Mimosa diplotricha in an adventive range over fourteen-repeated samples.

Table 3. Percentage contributions of pollinators on Mimosa diplotricha

\begin{tabular}{lll}
\hline & \multicolumn{2}{c}{ Percentage (\%) } \\
\cline { 2 - 3 } Taxon & Contribution & Cumulative \\
\hline Chalicodoma sp. & 44.5 & 44.5 \\
Xylocopa sp. & 20.2 & 64.7 \\
Apis mellifera & 12.8 & 77.5 \\
X. senior & 7.8 & 85.3 \\
Megachile sp. 1 & 4.3 & 89.6 \\
Amegilla sp. & 4.2 & 93.8 \\
Megachile sp. 2 & 2.6 & 96.4 \\
X. latipes & 1.0 & 97.4 \\
Eremnophila sp. & 0.8 & 98.2 \\
Polistes sp. & 0.8 & 98.9 \\
Danaus sp. & 0.7 & 99.6 \\
X. caffra & 0.3 & 99.9 \\
Helophilus pendulus & 0.2 & 100 \\
\hline
\end{tabular}




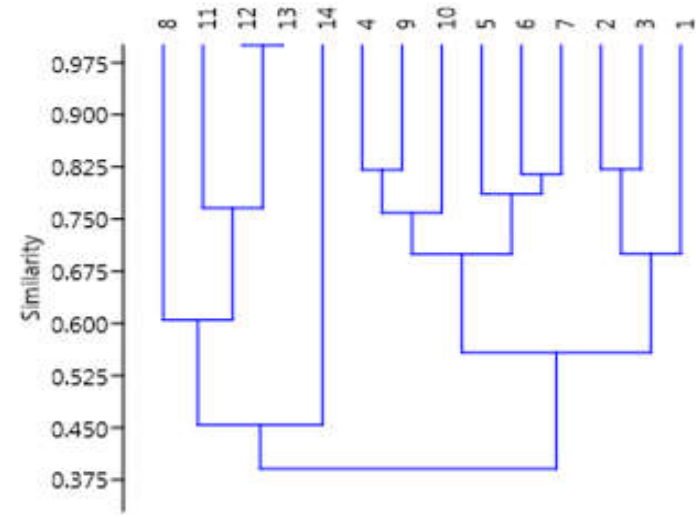

Fig 4. Hierarchical clustering of the composition of floral visitors found on Mimosa diplotricha by samples using Bray-Curtis similarity index.

A two-way dendrogram that was drawn based on BrayCurtis similarity index showed three groups of pollinators, the highly abundant species, the moderately abundant species and the singleton, Helophilus pendulus (top-right cluster: Fig. 7). The dendrogram further revealed a dissimilarity of species composition of less than $10 \%$ between samplings conducted $0930 \mathrm{~h}$ and 1130 $\mathrm{h}$, and less than $20 \%$ between community structure at $1230 \mathrm{~h}$ and the others, except that of $0830 \mathrm{~h}$, which was largely different (with ca. 40\% similarity to others (bottom-left: Fig 7). This study examined the composition and diversity of pollinators on the floral resource of $M$. diplotricha. Our expectations were that only a few pollinators would patronise the flowers of mimosa given its non-native status, but that did not hold as a considerable number was encountered, albeit of low diversity (as indicated by the effective diversity). The low diversity of pollinators utilising $M$. diplotricha indicates that the plant may not sustainably support the pollinators regardless of the short-term benefits. A plant's ability to support large diversity of pollinators for a relatively long period could be vital to both its proliferation and the survivability of its pollinators, if the floral resources of other plants -presumably the native one- are at least behaviourally selected against. Studies have shown that some pollinators are host-specific, while others are generalists that visit several flowers for pollen and nectar, and for the generalists, foraging behaviour may shift on account of food quality and quantity (Waser et al., 1996; Chittka and Schürchen, 2001; Sierra and Smith, 2009; Forester, 2010). In the case of those encountered here, the logical inference is that they are generalist pollinators given their propensity to utilise an introduced host, which they did not coevolved with ab initio.
Table 4. Diversity indices of floral visitor on M. diplotricha according to their visitation times

\begin{tabular}{llllll}
\hline & $0830 \mathrm{~h}$ & $0930 \mathrm{~h}$ & $1030 \mathrm{~h}$ & $1130 \mathrm{~h}$ & $1230 \mathrm{~h}$ \\
\hline Taxa & 9 & 11 & 12 & 10 & 11 \\
Individuals & 86 & 380 & 413 & 363 & 306 \\
Dominance & 0.37 & 0.34 & 0.32 & 0.32 & 0.38 \\
Shannon & 1.40 & 1.43 & 1.53 & 1.51 & 1.34 \\
Evenness & 0.45 & 0.38 & 0.38 & 0.45 & 0.35 \\
\hline
\end{tabular}

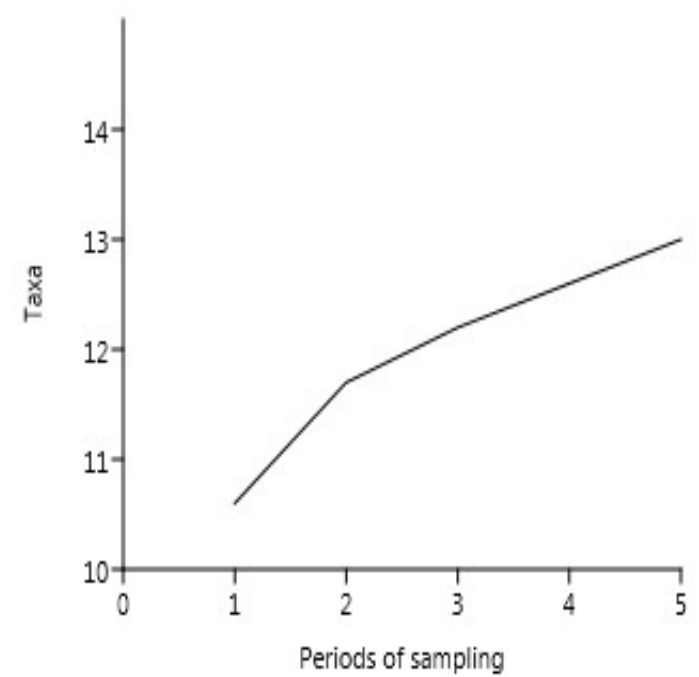

Fig 5. Rarefaction curve of species encountered for the five sampling periods during the survey. The cumulative number of insect species (taxa: $y$-axis) was plotted as a function of the cumulative sampling periods ( $x$-axis).

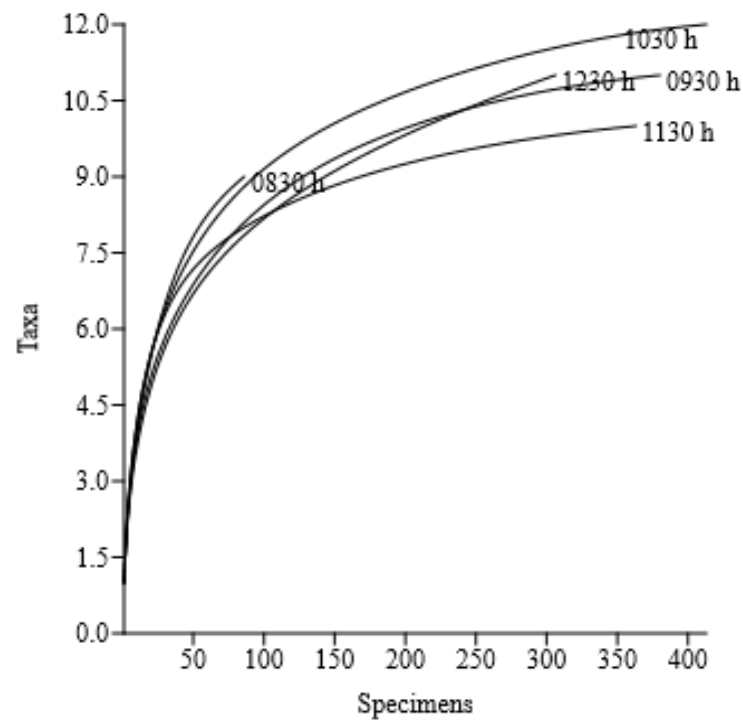

Fig 6. Individual rarefaction curve for the five sampling periods. The cumulative number of species (taxa: $y$-axis) was plotted as a function of the cumulative individual insect collected ( $x$-axis). 


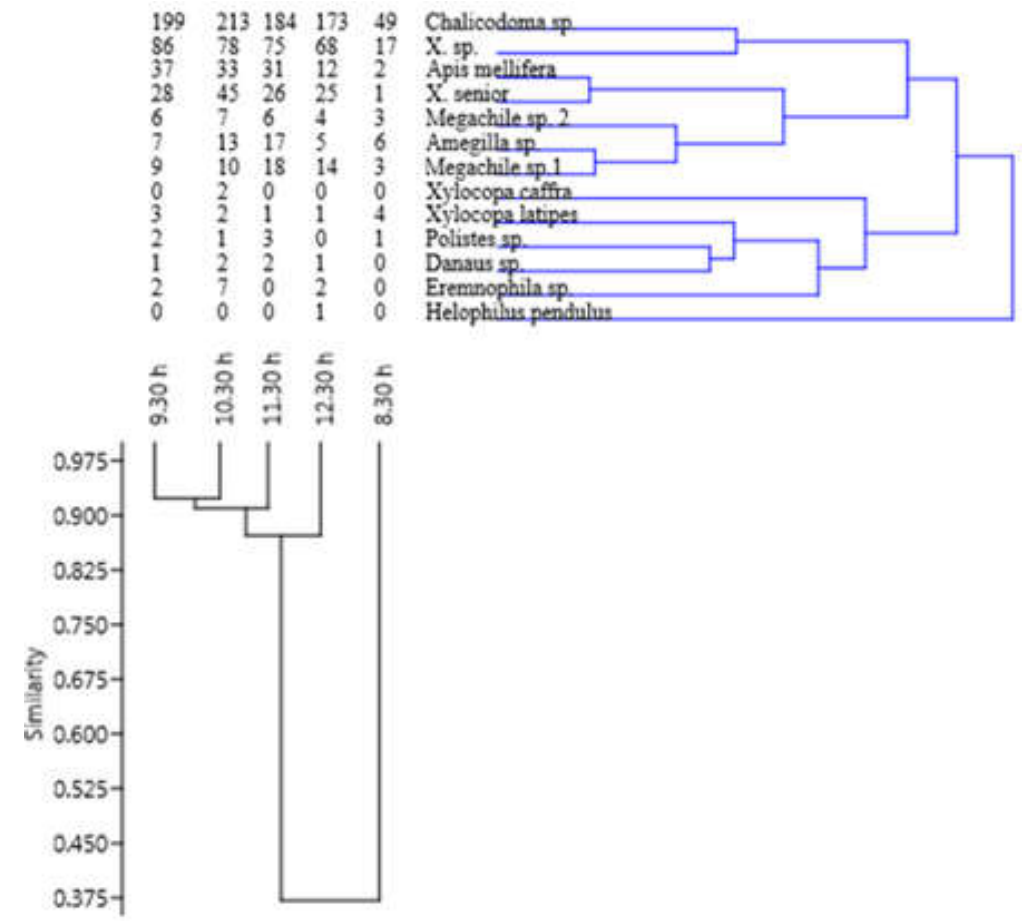

Fig 7. Two-way hierarchical clustering of floral visitors on Mimosa diplotricha according to their periodicity (bottom left dendrogram) and their abundance (top right dendrogram) using Bray-Curtis similarity index.

An increasing number of community-level studies suggest that, in floral host use, there are more generalists than specialists (see Stout and Tiedeken, 2017). Given the observed species richness and diversity on $M$. diplotricha, the key pollinators could be considered as generalists on an ecological ride through the host's floral resources, but it remains unclear whether such ride denies native flora of the associated services. Examples of such denial or compromise in ecosystem services had been demonstrated in Impatiens grandulifera that invade Europe where it competes for native pollinators through enhanced floral rewards that remarkably reduces seed set and fitness of neighbouring natives (Chittka and Schürkens, 2001). Although the pollinators' occurrence on $M$. diplotricha is high, not all of them may be important to the invasive plant as their relative contributions suggested, e.g., with the presence of singletons and doubletons. Nonetheless, in the presence of an abundant floral resource of $M$. diplotricha, the visiting-pollinators' services to native plants could be divested, and invested in the invasive plant (e.g., Chittka and Schürkens, 2001). Such a shift may speculatively be an ecological disservice to native plants, which may originally, in evolutionary sense, provide lesser amount of superior food quality (in their diverse forms) as opposed to many, but low quality monotonous food from a homogenous stand of invasive plants that may remarkably contribute to a decline in the pollinators' populations in the long run. Stout and Tiedeken's review showed that pollinators incur multilevel effects from invasive alien plants that affect their fitness, density, and species richness, diversity and composition, which could culminate in reduced pollination services; however, such reduction may only limit sexually reproductive native plants that cannot self pollinate or use other methods (Stout and Tiedeken, 2017).

With the presence of native pollinators (e.g., Apis mellifera amongst others) on $M$. diplotricha, our findings agree with previous studies in which invasive plants recruited native pollinators. For instance, invasive Hedysarum coronarium recruited honeybee Apis mellifera and Rhododendron ponticum recruited large bees Xylocopa violacea and Bombus species in Spain and in Ireland (Stout et al., 2006; Stout and Tiedeken, 2017). In some cases they even recruit more than they previously had in their native ranges, for example, the invasive Impatiens glandulifera that is serviced by several pollinators in its adventive range, is serviced by a small number of visitors of Bombus species in its native range (Chittka and Schürkens, 2001; see review: Stout and Tiedeken, 2017).

Taken together, the Order Hymenoptera appears to be the most important group of visiting pollinators and the most exploited by invasive alien flowering plants, which conforms to our observed pattern on M. diplotricha. High percentage contribution of any species represents dominance: in fact, Chalicodoma species, a hymenopteran, occurred most frequently in high 
percentage for which it was ranked the most important pollinating species on $M$. diplotricha -this is one of the golden threads of this study. The percentage contribution of Chalicodoma species was closely followed by Xylocopa species and X. senior, Apis mellifera, Amegilla species and Megachile species. Our findings are similar to the pollinators of Cajanus cajan in Cameroon where Chalicodoma cincta cincta, Xylocopa calens and A. mellifera were encountered in that order of decreasing dominance (Pando et al., 2011). Sierra and Smith (2009) noted Apis mellifera as the key pollinator on a sister host species, Mimosa pigra, contrary to our findings on $M$. diplotricha. With Chalicodoma's dominance on $M$. diplotricha, perhaps the different species attract different pollinators or that host use is influenced by localities: as Sierra and Smith's study was conducted in South America (believed to be the native range of mimosa) unlike ours in Africa. The floral-visiting species in the Orders Diptera and Lepidoptera (i.e., Helophilus pendulus and Danaus sp., respectively) were low in abundance. While $H$. pendulus was a singleton the latter was a doubleton; and such occurrences are symptomatic of occasional visitors or, plausibly, that their predilections for $M$. diplotricha is low relative to other neighbouring native plants.

Insect visitation on $M$. diplotricha showed that a maximum density at $1030 \mathrm{~h}$ (i.e., between $1000-1100 \mathrm{~h})$. Although the insect composition varies with time, findings here suggest that sampling conducted around the peak-density period will likely yield a more representative sample than other sampling times, especially the first sampling time, which formed a unique leaf on the dendrogram. Our finding agrees with the peak activity of Chalicodoma cincta cincta (at $0900 \mathrm{~h}$ and $1000 \mathrm{~h}$ ) observed on C. cajana in Yaoundé, Cameroon (Pando et al. 2011), though they had no records for $1000 \mathrm{~h}$ and $1100 \mathrm{~h}$; but there are more instances in literature (Tchindebe and Fohouo, 2014). Insect are highly dynamic within vegetation in response to weather, diurnal rhythm and food resource (e.g., Pando et al., 2011). As this study has shown, species composition and abundance largely changes over time (hourly or weekly) as the initial samples clustered differently from the later ones. This may not be unrelated to the plant phenology as the flower density may wane overtime. Knowledge of insects' periodicity is useful in determining their sampling time, which may be useful in other ecological studies. Mimosa's abundance close to agricultural farms offers two possibilities. Firstly, it offers a means to sustain pollinators until the floral resources of crops are available. Secondly, it could attract pollinators from native flora if there is a demonstrable preference for the non-native plant especially during the peak period. Most species observed on $M$. diplotricha have been reported as pollinators of major crops like Vigna unguiculata, Alium cepa and much more, which when pollinated by insects, e.g., Apis mellifera and Chalicodoma cincta cincta, enjoy improved yield and shelf life (Pando et al., 2011; Oronje et al., 201; Pando et al., 2014; Tchindebe and Fohouo, 2014). Apis species and Xylocopa species are major pollinators of bitter gourd, Momordica charanta (Oronje et al., 2012); sesame, Sesamum indicum (Mahfouz, 2012); and many other crops too numerous to mention (e.g., Tchindebe and Fohouo, 2014). It is possible that $M$. diplotricha can sustain these pollen visitors when the floral resources of agricultural crops are low; however, divesting their ecosystem services from economic plants in mosaics of invasive alien/native species, cannot be ruled out. While the former premise may enhance pollinators' conservation, the latter could negatively affect food productivity if reduced services of the pollinators translate to remarkable reductions in flower fertilization, seed and fruit settings as seen on $I$. grandulifera (cited above). Similarly, while the former may encourage the coexistence of $M$. diplotricha around farm lands, the latter does not. In fact, invasive alien plants are drivers of loss of biodiversity (MacDougall and Turkington, 2010; Bauer, 2012). Hence, their proliferation should not be encouraged, rather planting of other native flowering plants that can provide similar resources should be encouraged -as pollinators' activities are vital in ensuring food security.

The 'holy grail' of our findings is that $M$. diplotricha attracts relatively high number of native insect pollinators, whose ecosystem services when withdrawn by the invasive alien plants could be a potential undoing for native flowering plants, but may be in favour of the insects in the short run. Such possibility begs the question whether mimosa is not technically contributing to biodiversity, as it has been debated by some (Schlaepfer, 2018). To that our response is -no it does not, because of its negligible support for low species diversity. While mimosa may play an important role in provisioning the nutritional requirements of these pollinators and sustaining them with their abundant flowers, it should not be misconstrued as a justification for its cultivation as its sister species, $M$. pigra, is notoriously famous for being one of the world's 100 worst weeds that drives biodiversity loss (Lowe, 2002; MacDougall and Turkington, 2010; Bauer, 2012). One useful hypothesis of an unabated infestation of invasive mimosa to native pollinators is that it could pull the pollinators off native plants - a strategy that may further decimate the native plants, only for the invasive plant to dominate the rescinding space with an ever-increasing seed bank, which the pollinators facilitated. Given that several populations of pollinators are on a worldwide decline while the invasive alien plants expand their ranges suggest that the flowering invasive alien plants 
will continually engage native pollinators and redirect their ecological services from native plants. However, how the floral resources of invasive flowering plants within a mosaic of native flowering plants are chosen by native pollinators remains unclear and necessitates two questions: do the native flower visitors (i) randomly (or facultative) utilise the invasive resources or (ii) selectively (or obligatorily) choose them over the native ones? These are questions that remain to be answered. While an affirmation of the former may be the lesser of two evils relative to that of the latter, both ways the devils are in the details. Nonetheless, it is also possible that the pollinators are simply ecological passersby with no preference for the pollen of invasive alien plants $-\mathrm{a}$ doubtful hypothesis though, until empirically tested. In conclusion, $M$. diplotricha recruits several agriculturally important native pollinators to its flowers and as regards whether it really matters, yes it does.

Acknowledgement: Thanks are due to the officials of the university security unit for the right of way given to access the study site beyond 'Capitol'. No external funding was sourced for this study.

\section{REFERENCES}

Bauer, JT (2012) Invasive species: "back-seat drivers" of ecosystem change? Biol. Inv. 14: 1295-1304.

Beismeijer, JC; Roberts, SPM; Reemer, M; Ohlemueller, R; Edwards, M; Peeters, T; Schaffers AP; Potts, SG; Kleukers, R; Thomas, CD; Settele, J; Kunin, WE (2006) Parallel declines in pollinators and insectpollinated plants in Britain and The Netherlands. Sci. 313: 351-354.

Bland, RG; Jacque, HE (1978) How to know the insects. Waveland Press Inc. USA. 409pp.

Chittka, L; Schürkens, S (2001) Successful invasion of a floral market. Nat. 411: 653

Ekhator, F; Uyi, OO; Ikuenobe, CE; Okeke, CO (2013) The distribution and problems of the invasive alien plant, Mimosa diplotricha C. Wright ex Sauvalle (Mimosaceae) in Nigeria. Am J Pl Sci. 4: 866-877.

Forester, M (2010). A comparison of pollinator landing on Lantana camara with three other plant species in bloom at forest trails, Karnataka, India. Available at http://india.ku.edu/nature/documents/MelissaForest er.pdf

Gess, SK; Gess, FW (2014) Wasps and bees in southern Africa. South African National Biodiversity Institute (SANBI) Biodiversity Series 24, 320pp
Ghazoul, J (2002) Flowers at the front line of invasion. Ecol. Ent. 27: 638-640

Lonsdale, WM (1988) Litter fall in an Australian population of Mimosa pigra, an invasive tropical shrub. J Trop Ecol. 4: 381-392.

Lopezaraiza-Mikel, ME; Hayes, RB; Whalley, MR; Memmott, J (2007). The impact of an alien plant on a native plant-pollinator network: an experimental approach. Ecol Lett. 10: 539-550.

Lowe, S; Browne, M; Boudjelas, S; DePoorter, M (2000) 100 of the World's worst invasive alien species. A selection from the Global Invasive Species Database. The Invasive Species Specialist Group (ISSG) a specialist group of the Species Survival Commission (SSC) of the World Conservation Union (IUCN), 12pp.

Macdougall, AS; Turkington, R (2010) Are invasive species the drivers or passengers of change in degraded ecosystems? Ecol. 86: 42-55.

Mahfouzl, HM; Kamel, SM; Belal, AH; Said, M (2012) Pollinators visiting sesame (Sesamum indicum L.) seed crop with reference to foraging activity of some bee species Cerc Agr în Mol. 14(2): 49-55.

Memmott, J; Waser, NM (2002) Integration of alien plants into a native flower-pollinator visitation web. Proceedings of the Royal Society of London Series B-Biol Sci. 269: 2395-2399.

Morague, E; Traveset, A (2005) Effect of Carobrotus spp. On the pollination success of native plant species of the Balearic Islands. Biol Cons. 122: 611619.

Olesen, J; Jordano, P (2002) Geographic patterns in plant-pollinator mutualistic networks. Ecol 83: 2416-2424.

Oronje, MLO; Hagen, M; Gikungu, M; Kasina, M; Kraemer, M (2012) Pollinator diversity, behavior and limitation on yield of karela (Momordica charantia L. Curcubitaceae) in western Kenya. Afri J Agric Res. 7: 1629-1638.

Owen, J (1991) The Ecology of a Garden; the First Fifteen Years. Cambridge University Press, Cambridge. 403pp.

Pando, JB; Fernand-Nestor, TF; Tamesse, JL (2011) Pollination and yield responses of pigeon pea (Cajanus cajan L. Mill sp.) to foraging activity of 
Chalicodoma cincta cincta (Hymenoptera: Megachilidae) in Yaoundé (Cameroon). J. Ani and Pl Sci. 11:1346-1357.

Pando, JB; Fohouo, FT; Djonwangwe, D; Tamesse, JL (2014) The importance of single floral visit of Chalicodoma cincta cincta Fabricius 1871 (Hymenoptera: Megachilidae) in the pollination and yield of Vigna unguiculata (L.) Walp. 1843 (Fabaceae) in Cameroon. Intl J Agron and Agric Res. 4: 179-187.

Schlaepfer, MA (2018) Do non-native species contribute to biodiversity? PLoS Biol 16(4): e2005568.

Sierra, CIA; Smith, HAB (2009) Bees visiting Mimosa pigra L. (Mimosaceae): foraging behavior and pollen loads. Acta Biol Colom. 14(1): 109-120.

Stout, JC; Tiedeken, EJ (2017). Direct interactions between invasive plants and native pollinators: evidence, impacts and approaches. Fun Ecol. 31: 38-46.
Stout, JC; Parnell, JAN; Arroyo, J; Crowe, TP (2006) Pollination ecology and seed production of Rhododendron ponticum in native and exotic habitats. Biod and Cons. 15: 755-777.

Swart, RC; Pryke, JS; Roets, F (2017) Optimising the sampling of foliage arthropods from scrubland vegetation for biodiversity studies. Afri Ento. 25(1): 164-174.

Tchindebe, G; Fohouo, FT (2014) Foraging and pollination activity of Apis mellifera adansonii Latreille (Hymenoptera: Apidae) on flowers of Allium cepa L. (Liliaceae) at Maroua, Cameroon. Intl J Agron and Agric Res. 5: 139-153.

Waser, NM; Chittka, L; Price, MV; Williams, NM; Ollerton, J (1996) Generalization in pollination systems and why it matters. Ecol. 77: 1043-1060.

Williamson, M; Fitter, A (1996). The varying success of invaders. Ecol. 77: 1661-1666. 